\title{
Affordances de tecnologias digitais para o desenvolvimento de habilidades orais em inglês
}

\section{Affordances of digital technologies for the development of oral skills in English}

Ronaldo Corrêa Gomes Junior*

Universidade Federal de Minas Gerais - UFMG

Belo Horizonte - Minas Gerais/Brasil

Gabriela Santos Teixeira**

Universidade Federal de Minas Gerais - UFMG

Belo Horizonte - Minas Gerais/Brasil

Mayra Garcia da Silva***

Universidade Federal de Minas Gerais - UFMG

Belo Horizonte - Minas Gerais/Brasil

Cynthia Maria Aguilar Paulino****

Universidade Federal de Minas Gerais - UFMG

Belo Horizonte - Minas Gerais/Brasil

\begin{abstract}
RESUMO: O desenvolvimento das habilidades orais em língua estrangeira enfrenta muitas dificuldades no contexto educacional brasileiro, nas modalidades tanto presencial quanto a distância, o que indica uma demanda por maneiras efetivas de ensinar e aprender habilidades orais em inglês. Abordando uma perspectiva ecológica, esta pesquisa buscou investigar as affordances de tecnologias digitais para desenvolver as habilidades orais em língua inglesa por meio das percepções de estudantes de Letras da Universidade Federal de Minas Gerais que usaram ferramentas e aplicativos da internet para realizar tarefas semanais de uma disciplina on-line. Para o grupo de aprendizes em questão, as tecnologias digitais interativas permitiram o planejamento e a (re)gravação de suas produções orais, assim como a prática da compreensão oral, possibilitando que eles identificassem seus erros e dificuldades.
\end{abstract}

\footnotetext{
* ronaldocgomes@gmail.com

** gabyletrasufmg@gmail.com

*** mastreg@hotmail.com

**** cynthia.map@gmail.com
} 
PALAVRAS-CHAVE: affordances; habilidades orais; língua inglesa; tecnologias digitais.

\begin{abstract}
Both in face-to-face and distance learning, the development of oral skills in foreign languages faces many difficulties in the Brazilian educational context, which indicates a great demand for effective ways of teaching and learning oral English skills. From an ecological perspective, this study aimed at investigating the affordances of digital technologies for developing oral skills in English through the perceptions of Languages and Literature students of the Federal University of Minas Gerais that used internet tools and apps to do weekly assignments from an online course. For this group of learners, the digital interactive technologies allowed them not only to plan and (re)record their oral production, but also to practice the oral comprehension, being capable of identifying their mistakes and difficulties.
\end{abstract}

KEYWORDS: affordances; oral skills; English language; digital technologies.

\title{
1 Introdução
}

O desenvolvimento das habilidades orais em língua estrangeira pode ser considerado um caminho tortuoso no contexto educacional brasileiro. Essa parece ser uma realidade tanto na modalidade presencial como na modalidade a distância. De acordo com Paiva (2014), embora a tecnologia de voz esteja acessível desde a década de 1990, não houve investimento significativo dos pesquisadores em sua utilização no desenvolvimento das habilidades orais no ensino de línguas estrangeiras.

Essa dificuldade pode ser atribuída a muitos fatores, como a curta duração das aulas, o grande número de alunos, a falta de recursos tecnológicos, a limitação da proficiência de professores etc. Dessa maneira, há uma grande demanda por estudos que busquem por maneiras efetivas de ensinar e aprender habilidades orais em inglês que possam driblar muitos dos fatores considerados como obstáculos ao desenvolvimento da oralidade.

A perspectiva ecológica da teoria psicológica de Gibson (1986) vem sendo utilizada para entender alguns fenômenos, como a aprendizagem de línguas. Van Lier (2002) sugere que uma abordagem ecológica pode unir um grande número de visões sobre a aprendizagem de línguas, especialmente quando essa abordagem é vinculada a uma visão de mundo ecológica. Para o autor, a abordagem ecológica para a aprendizagem de línguas desafia três premissas. Primeiramente, ela muda a ênfase do reducionismo científico para a noção de emergência. Ao invés de assumir que os fenômenos possam ser explicados em termos de componentes mais simples, ela considera que em 
cada nível de desenvolvimento emergem propriedades que não podem ser reduzidas àquelas dos níveis iniciais. Em segundo lugar, em uma perspectiva ecológica, nem toda a cognição e aprendizagem pode ser explicada por processos que ocorrem em de nossas mentes. Por fim, a ecologia assegura que as atividades perceptuais e sociais do aprendiz, principalmente as interações, são centrais para o entendimento da aprendizagem. Dessa maneira, para o autor, elas não só facilitam a aprendizagem, elas são a aprendizagem.

A noção de affordance vem da psicologia ecológica de Gibson (1986), que sugere, entre outras coisas, que os indivíduos devem ser considerados inseridos em seus mundos biológicos e ambientes; e esses como pertencentes à ecologia. Para o autor, "as affordances de um ambiente são o que ele oferece para o animal, o que ele provém ou fornece, tanto para o bem quanto para o

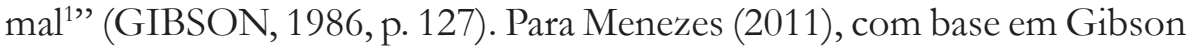
(1986), affordances estão intimamente ligadas à ideia de percepção e ação. Nessa perspectiva, a percepção não é vista como uma capacidade mental, mas como um fenômeno ecológico, o resultado da interação dos animais no ambiente. Dessa maneira, os agentes de um ambiente percebem o que um nicho oferece, interpretam as affordances e agem sobre elas. Portanto, concordamos com a autora quando afirma que a língua(gem) oferece affordances que são restritas à percepção dos usuários.

Este artigo é fruto de uma pesquisa cujo objetivo foi investigar as affordances de tecnologias digitais para o desenvolvimento de habilidades orais e inglês mediadas pelo computador e/ou dispositivos móveis. Em outras palavras, buscamos investigar as oportunidades de ação encontradas em ferramentas e ambientes digitais para desenvolver a compreensão e produção oral na língua estrangeira. Para isso, analisamos as percepções de estudantes de uma disciplina on-line da graduação em Letras de uma universidade federal, que usaram ferramentas e aplicativos da internet para realizar tarefas semanais. Analisando o discurso dos estudantes, destacamos enunciados que pudessem revelar affordances referentes ao desenvolvimento das habilidades orais dos estudantes.

\footnotetext{
${ }^{1}$ No original: "The affordances of the environment are what it offers the animal, what it provides or furnishes, either for good or ill".
} 


\section{Fundamentação teórica}

Nesta seção, contextualizamos a pesquisa fazendo um panorama sobre a perspectiva ecológica (VAN LIER, 2002, 2010). Em seguida, apresentamos o conceito de affordance, estabelecendo sua relação com a Linguística Aplicada, mais especificamente com o ensino e a aprendizagem de línguas. Por fim, apresentamos alguns outros estudos que pesquisaram o desenvolvimento de habilidades orais em língua estrangeira por meio de tecnologias digitais.

\subsection{Perspectiva ecológica}

De acordo com van Lier (2002), a perspectiva ecológica desafia a abordagem científica tradicional, uma vez que esta tende a ser muito pontual e restrita em suas análises. Na perspectiva ecológica aplicada à aprendizagem de línguas, o sujeito é concebido como imerso em um ambiente repleto de significados em potencial, os quais se tornam disponíveis à medida em que ele interage com o ambiente a sua volta. Para esse autor, a percepção e a interação do sujeito com o ambiente são essenciais para o seu desenvolvimento cognitivo e aquisição da nova língua. Ele defende que uma análise mais completa da aprendizagem de línguas deve observar e avaliar esses fatores (VAN LIER, 2002).

A perspectiva ecológica permite uma visão ampla do problema que propomos analisar. O processo de aprendizagem é complexo e envolve não somente o indivíduo e sua história, mas também as relações que ele estabelece com outros indivíduos e com o ambiente de aprendizagem. De acordo com van Lier (2004), nessa perspectiva, a aprendizagem não é compreendida como recepção de conhecimentos, mas como um processo de gerenciamento e avaliação. Em consonância, Menezes (2011) nos mostra que as experiências dos aprendizes vêm ganhando notoriedade nas pesquisas em Linguística Aplicada. Quando se trata da aprendizagem de línguas, existem muitas relações que precisam ser compreendidas, pois o estudante acaba sendo apresentado a outras culturas e os contatos estabelecidos por meio da segunda ou outra língua somam-se àqueles ligados à primeira língua (VAN LIER, 2004; MENEZES, 2011).

De acordo com Murray e Fujishima (2013, p. 142), quando se trata de pesquisas a partir da perspectiva ecológica, existem alguns aspectos importantes a serem considerados. A pesquisa deve "ser contextualizada e focar nas relações dentro de um ambiente em particular assim como nas 
relações dos indivíduos com o ambiente", "considerar fatores de tempo e espaço", "ter o potencial de apresentar intervenções" e "ser válida ecológica e fenomenologicamente, adotando uma perspectiva êmica na qual as noções e construtos analíticos usados sejam compatíveis com aqueles adotados pelos participantes" (VAN LIER, 2004 apud MURRAY E FUJISHIMA, 2013). Dessa forma, para os autores, o pesquisador deve estar mais atento ao participante da pesquisa e à forma como ele descreve seu contexto e suas interações com ele do que com possíveis generalizações acerca do ambiente e suas affordances. A experiência dos sujeitos é mais importante do que criar leis como: "a exposição a esse ambiente faz com que os indivíduos atuem de determinada forma". Cada sujeito terá uma interpretação diferente do mundo, que depende de suas experiências anteriores. Portanto, criar uma generalização sobre um ambiente e as affordances que ele oferece pode ser limitador.

Kennewell (2001) também mostra como os conceitos da perspectiva ecológica podem ser utilizados para avaliação de metodologias em sala de aula. O autor considera que o papel do professor é orquestrar affordances e constraints de forma a guiar a aprendizagem dos alunos. No entanto, a forma como ele guia oferece diferenças nos resultados apresentados. Ele oferece o exemplo de uma mesma tarefa realizada por três professores diferentes e que instruíram os alunos de formas diferentes, ou seja, com mais ou menos constraints. Quando houve menos limitações, os resultados apresentados pelos alunos foram mais variados e eles puderam discutir mais profundamente o tema apresentado, enquanto onde a pesquisa foi mais guiada, os resultados apresentados foram muito parecidos e não houve discussão sobre o tema.

\subsection{O conceito de affordance}

O conceito de affordance é importante para explicar as relações entre o sujeito e o ambiente no qual está inserido. De acordo com Gibson (1986), affordances são relações complementares entre indivíduo e ambiente. O termo compreende a relação que passa pela percepção e ação do sujeito, na medida em que ele entende o que o ambiente pode oferecer e como ele precisará agir para que suas necessidades sejam atendidas. Para o psicólogo americano, em um mesmo ambiente podem existir inúmeras affordances, mas a percepção delas depende do indivíduo, de sua história de vida e das suas necessidades no momento de contato com o ambiente. Por exemplo, uma árvore pode oferecer diferentes affordances para diferentes animais: ela pode abrigar em 
seu interior pequenos mamíferos e aves, fornecer alimentos para animais maiores e oferecer sombra para caçadores. Depende do indivíduo em si, a forma com a qual cada um vai se aproximar e utilizar o que lhe é ofertado.

Partindo da perspectiva ecológica, Menezes (2011) nos mostra a relação entre o conceito de affordance e a experiência do aluno no processo de aprendizagem. De acordo com a autora, esse conceito e a perspectiva ecológica mudaram a forma como a aprendizagem de línguas é compreendida, pois entende os processos cognitivos, sociais e sensoriais como aspectos integrados no processo de aprendizagem e não como fatores isolados. Em seu texto, a autora apresenta várias definições de affordances que nos ajudam a perceber a importância do conceito na Linguística Aplicada. Destacamos aqui as definições de Stoffregen (2003) e Chemero (2003). Para Stoffregen (2003, p. 115), "affordances são propriedades do animal-ambiente, ou seja, são propriedades emergentes que não são inerentes nem ao ambiente nem ao animal". Nessa perspectiva, elas seriam centrais para a abordagem ecológica da percepção-ação. No âmbito desta pesquisa, isso quer dizer que não se pode falar que uma ferramenta ou ambiente digital tem determinada affordance, mas que os aprendizes perceberam neles aquela possibilidade de ação. Segundo Chemero (2003, p. 181), "affordances são relações entre as habilidades do organismo e as características do ambiente" e, enquanto relações, são tanto reais quanto percebidas. Dessa forma, as interações precisam ser consideradas não apenas do ponto de vista do estudante ou da plataforma utilizada, mas como um todo.

Ao referir-se à superfície terrestre, Gibson (1986) menciona que o meio (ar) oferece diversas affordances, tais como a respiração e a locomoção. Ele emprega o termo "substâncias" para descrever matérias sólidas e fluidas, que, de acordo com suas características, possuem diferentes affordances: os sólidos como superfície ou objeto; a líquida como solvente ou bebida, por exemplo. As superfícies, por sua vez, se horizontais, têm como affordance, por exemplo, ser um apoio para as substâncias se equilibrarem; já as superfícies verticais, como parede, podem ter a affordance de ser uma barreira à locomoção (GIBSON, 1986).

Em relação aos animais e às pessoas, Gibson (1986) reconhece que suas affordances são as mais complexas do ambiente, pois eles interagem com o observador e entre si. Um comportamento tem como affordance uma reação, outro comportamento recíproco (affordances mútuas). Dessa forma, ele utiliza o conceito de "nicho" como um conjunto de affordances de um 
determinado ambiente para um animal específico. Um nicho é único para cada animal, e cada animal tem seu próprio nicho; eles se complementam.

O processo de aprendizagem depende dos contextos nos quais o estudante está inserido, de como ele percebe o processo e as ferramentas utilizadas para a aprendizagem e também afeta a forma como ele se relaciona com o ambiente. Portanto, a compreensão de affordance na área da Linguística Aplicada, especialmente para o ensino de línguas, é importante para entender os vínculos criados pelos sujeitos com a(s) língua(s) que aprende(m), bem como com as ferramentas utilizadas para essa finalidade.

\subsection{Habilidades orais}

Os alunos de inglês, principalmente de nível básico, têm dificuldade em perceber seu progresso no conhecimento da língua. Dessa forma, de acordo com Seligson (1999), é importante que o professor deixe claro os objetivos a serem atingidos pelos alunos em relação à aprendizagem ou produção durante o semestre para que eles não fiquem frustrados e desmotivados diante da não fluência na língua. Para o autor, essas metas devem ser realistas e mensuráveis de forma que os alunos possam efetivamente comprovar que avançaram no seu entendimento de inglês.

Além de estarem conscientes sobre os objetivos a serem alcançados, os alunos também precisam perceber a relevância de se aprender uma outra língua, uma vez que o engajamento dos estudantes é determinante para a aprendizagem. Com base nisso, o autor destaca a importância de o professor preparar aulas interessantes e de abordar temas de contextos significativos para os alunos, para então instigá-los e motivá-los a desenvolver a habilidade oral (SELIGSON, 1999). Acreditamos que uma forma de fazer com que os estudantes percebam os objetivos das tarefas, notem seus avanços e enxerguem a relevância da aprendizagem seja por meio do uso de tecnologias digitais.

A pesquisa de Volle (2005) investigou a aquisição de habilidades orais em um curso on-line de espanhol. Para isso, a pesquisadora analisou a produção da pronúncia em dois tipos de atividades on-line de fala e em duas conversas on-line em tempo real (todas gravadas). Para determinar se a pronúncia dos estudantes estava melhorando no decorrer do curso, a autora comparou a performance dos estudantes no início e no fim do curso. Além disso, os alunos participaram de duas conversas virtuais por meio do MSN Messenger, uma no meio e outra no fim do semestre. Três 
tipos de dados foram gerados: uma pontuação de articulação (articulação = pronúncia, estresse e entonação), de precisão e de proficiência. Os resultados da pesquisa de Volle (2005) sugerem que os ganhos significativos ocorreram somente na pontuação de proficiência. Para a autora, atividades orais síncronas on-line e entrevistas orais on-line são experiências valiosas para os estudantes e oferecem registros permanentes de seus desenvolvimentos.

Hui-Yin, Shiang-Kwei e Comac (2008), em um estudo piloto, investigaram como o uso de audioblogs pode ajudar os professores a melhorar as suas instruções. Nesse estudo, o professor utilizou essa ferramenta para propor atividades orais, interagir com seus aprendizes e avaliar a performances das produções dos alunos. Os aprendizes gravaram suas atividades em seus telefones celulares e mantiveram um audioblog individual, para o qual enviavam os arquivos de áudio. O professor interagiu com os estudantes por meio desses audioblogs para auxiliá-los de acordo com suas necessidades. Utilizando uma metodologia mista (survey, questionário aberto, entrevistas e análise dos blogs), os autores pesquisaram como a interação do professor por meio dos audioblogs melhorou a performance oral dos aprendizes. Os resultados sugerem que o uso dessa atividade vai ao encontro das necessidades instrucionais do professor, promovendo maneiras eficientes de avaliar a produção oral dos alunos e permitindo um feedback individualizado. Os estudantes demonstraram gostar do conforto em usar audioblogs, além de acreditar que essa experiência de aprendizagem foi proveitosa.

Petrakou (2010), em um estudo etnográfico, aponta que o ambiente virtual oferece possibilidades para interação para os estudantes, mas ele não serve como o único ambiente de aprendizagem, pois ainda existem muitas informações que precisam ser filtradas para que a aprendizagem ocorra, além de problemas técnicos que podem atrapalhar a interação. Como mostram seus resultados, obtidos por meio de observações, gravações e entrevistas, é necessário que, além das interações sincrônicas que ocorrem nos ambientes virtuais, também ocorram avaliações e interações assincrônicas.

Chen (2011) investigou a Microsoft Speech Application Software Development Kit (SASDK), uma ferramenta gratuita que pode ser utilizada para desenvolver páginas da web para o treinamento de habilidades orais para aprendizes de inglês como língua estrangeira. Essas páginas continham seis tipos diferentes de exercícios on-line que permitiam aos estudantes praticar a fala e obter feedback imediato sobre suas performances. $\mathrm{O}$ autor investigou um grupo de 25 estudantes universitários e outro grupo de 35 
professores de inglês em formação por meio de dois questionários. Os resultados do estudo indicam que a maioria dos participantes gostou de usar os websites e achou que eles ajudaram a melhorar suas habilidades orais em inglês. Os participantes também destacaram que o ponto forte do sistema é o oferecimento de diversos tipos de exercícios que podem encorajar os aprendizes a produzir mais em um ambiente com menos ansiedade. As maiores limitações foram os feedbacks insuficientes e os padrões desafiadores a serem seguidos para poder completar a atividade.

O estudo de Dias e Pimenta (2015) foi conduzido em uma disciplina de 60 horas para vinte professores em serviço. Nesse curso, havia a integração entre aulas presenciais e on-line, nas quais os alunos gravavam suas tarefas usando aplicativos e ferramentas da internet e as disponibilizavam para feedback entre seus colegas e professores. Dentre as tarefas, havia a gravação de apresentações pessoais, entrevistas e documentários. Os resultados revelam que os professores pré-serviço melhoraram suas habilidades orais por meio da reflexão crítica do uso de ferramentas digitais para a produção de gêneros orais. Essa prática oral permitiu aos estudantes tempo adicional para preparar, checar pronúncias, gravar e regravar suas observações tornando a aprendizagem um processo de construção entre eles.

\section{Metodologia}

Esta é uma pesquisa qualitativa de natureza interpretativista. Como afirma Dörnyei (2007), os procedimentos da pesquisa qualitativa geram dados primariamente abertos e não numéricos que são, em um segundo momento, analisados por métodos não estatísticos. Denzin e Lincoln (2006) destacam que a transdisciplinaridade é uma característica marcante dessa metodologia, já que ela atravessa diversos campos e temas. Para os autores, embora as definições variem de acordo com contexto e momento histórico das pesquisas, pode-se pensar na seguinte definição:

[A] pesquisa qualitativa é uma atividade situada que localiza o observador no mundo. Consiste em um conjunto de práticas materiais e interpretativas que dão visibilidade ao mundo. [...] [A] pesquisa qualitativa envolve uma abordagem naturalista, interpretativa, para o mundo, o que significa que seus pesquisadores estudam as coisas em seus cenários naturais, tentando entender, ou interpretar, os fenômenos em termos dos significados que as pessoas a eles conferem (DENZIN; LINCOLN, 2006, p. 23). 
Nessa perspectiva uma abordagem qualitativa privilegia as qualidades das entidades e os processos e significados que não são passíveis de serem quantificados e/ou medidos experimentalmente. Algumas características dessa abordagem são: (a) ênfase na construção social da realidade; (b) relação extremamente íntima entre o pesquisador e a realidade a ser estudada; (c) a consideração das limitações que surgem durante o processo de investigação. Em suma, abordagens qualitativas "buscam soluções para as questões que realçam o modo como a experiência social é criada e adquire significado" (DENZIN; LINCOLN, 2006, p. 23). Dessa maneira, a pesquisa apresentada neste artigo adota a abordagem qualitativa por entendermos que as affordances das tecnologias digitais são construções sociais: percepções e experiências (re)criadas na interação dos participantes com as ferramentas, aplicativos e ambiente virtual.

\subsection{Contexto e participantes}

Para a condução dessa pesquisa, tivemos como participantes os alunos de uma disciplina on-line a distância planejada e ministrada pelos professores Vera Menezes de Oliveira e Paiva e Ronaldo Corrêa Gomes Junior na Faculdade de Letras da Universidade Federal de Minas Gerais, cujo objetivo era o desenvolvimento de habilidades orais por meio de tecnologias digitais. Oferecido em caráter optativo no segundo semestre letivo de 2016, o curso de quinze semanas ocorreu em um ambiente virtual (plataforma Moodle) e convidava os alunos a desenvolverem tarefas baseadas em gêneros orais e funções básicas, como apresentar-se, descrever lugares, dar opiniões, expressar sentimentos e falar sobre o passado e o futuro. Para o desenvolvimento das tarefas, os alunos poderiam contar com o uso de ferramentas digitais como: Voki (criação de avatares), Vocaroo (gravação de áudio), Fotobabble (criação de fotos narradas), PowToon, (criação de vídeos narrados), UTellStory (criação de apresentação de slides narradas) e Voice'Thread (discussões em áudio em torno de arquivos).

Inicialmente havia setenta alunos matriculados em duas turmas (reunidos em uma meta turma, ou seja, uma grande junção das duas turmas onde todos interagiam), mas apenas 59 continuaram na disciplina até o final. Desses, 53 autorizaram o uso de suas tarefas para fins de pesquisa acadêmica. Os nomes verdadeiros dos estudantes foram substituídos por pseudônimos. 


\subsection{Instrumentos de geração de dados}

a) Diário:

Ao longo da disciplina, os alunos escreveram reflexões sobre suas experiências na realização das tarefas semanais, registrando suas percepções, dúvidas, opiniões e comentários sobre as atividades e respectivas ferramentas digitais. Essa tarefa foi realizada em português. Foi desenvolvido um roteiro para orientar os estudantes na narrativa. Para que affordances das tecnologias emergissem, alguns tópicos foram criados para orientar os participantes a refletir sobre suas estratégias, emoções e percepções em relação à aprendizagem. Os diários eram submetidos em uma seção especial do ambiente de aprendizagem no Moodle e não ficam disponíveis para os demais participantes, sendo lidos apenas pelos professores.

b) Narrativa de aprendizagem:

Uma das tarefas do curso foi o desenvolvimento da história de aprendizagem de cada membro. Nessa tarefa, os estudantes foram convidados a narrar sobre seus processos de ensino e aprendizagem de inglês em geral e também sobre suas experiências ao lidar com as ferramentas digitais utilizadas. Para desenvolver a história de aprendizagem, os participantes também contaram com o apoio de um roteiro, em que um dos itens perguntava sobre a percepção dos estudantes sobre o impacto das tecnologias digitais para o desenvolvimento de suas habilidades orais.

c) Autoavaliação:

Os estudantes fizeram uma autoavaliação em relação à experiência, no final do curso. Nela, os participantes foram convidados a comparar a primeira com as últimas produções orais na disciplina e dizer se consideram que houve algum avanço em termos de uso da língua e de segurança e naturalidade na produção oral. Eles também disseram o que aprenderam durante essa experiência.

\subsection{Procedimentos de análise}

A análise dos dados seguiu os parâmetros e procedimentos da pesquisa qualitativa (DÖRNYEI, 2007). Primeiramente, houve a busca por unidades significativas (HOLIDAY, 2002), ou seja, enunciados que revelassem as affordances das tecnologias para os alunos. Após repetidas leituras, esses 
enunciados foram categorizados de acordo com suas regularidades. Em seguida, foram criadas categorias que agrupam as affordances percebidas nas tecnologias por esse grupo de aprendizes para desenvolver habilidades orais.

\section{Resultados alcançados e discussão}

Nesta seção apresentamos as categorias de affordances mais regulares deste estudo. Elas nos possibilitam entender como esse grupo de participantes percebe as oportunidades de aprendizagem e desenvolvimento de habilidades orais por meio de tecnologias digitais. É importante ressaltar que as affordances estão bastante conectadas e entrelaçadas umas nas outras, não sendo possível isolá-las. As percepções de oportunidades de ação ocorrem, na maioria das vezes, simultaneamente ou concomitantemente.

Em seus diários, os participantes da pesquisa destacaram questões emocionais de maneira recorrente, mencionando, por exemplo, como se sentiam mais confiantes e desinibidos em praticarem sozinhos e não sob o possível julgamento dos colegas. No entanto, apesar de serem algo que eles entendem como possibilidades oferecidas pelas ferramentas e pelo ambiente digital, não compreendemos essas oportunidades como affordances nesta pesquisa, e sim como emoções intimamente relacionadas ao reconhecimento e ação sobre as affordances, como apontam os estudos de Aragão (2017) e de Aragão, Paiva e Gomes Junior (no prelo).

Para fins didáticos, iremos analisar e ilustrar as affordances mais regulares neste estudo, separadamente. Entretanto, a voz dos participantes ilustrará como elas são interligadas e sinalizam caminhos traçados por eles para desenvolverem suas habilidades orais em língua inglesa. A ordem de apresentação das affordances seguirá sua regularidade.

\subsection{Planejar produção oral}

Os alunos participantes da pesquisa perceberam como uma das affordances a possibilidade de planejar a produção oral, ou seja, escrever o que iriam falar e explorar as ferramentas, para conhecê-las, antes de realizar a gravação. Essa é uma affordance que geralmente não é percebida durante a comunicação face a face, mas que as tecnologias digitais possibilitam. Além disso, ao planejar a produção, os aprendizes também podiam explorar novos vocabulários e checar se as estruturas escolhidas para a tarefa eram adequadas. A seguir, estão alguns excertos que ilustram essa categoria de affordance: 
1. Em cada atividade escrevi um script para depois gravar o áudio. Antes de gravar o áudio em si, explorei bastante cada ferramenta para saber o que era possível fazer em cada uma delas. Gravei entre duas e três vezes o áudio para ter certeza se o conteúdo sairia do jeito que eu queria. (Alice)

2. Antes de fazer a atividade, eu fiz um script e reli ele muitas vezes para ter certeza que eu tinha acertado todos os detalhes. Depois de gravar uma vez, eu postava no Moodle. Eu geralmente não usei ferramentas Text to Speech. (Bianca)

3. Primeiro fiz um roteiro descrevendo minha rotina, depois utilizei a ferramenta Text to Speech e, por fim, gravei meu áudio. Só precisei gravar uma vez para essa atividade. Também escutei a rotina de alguns colegas para conhecê-los melhor. (Andressa)

O discurso de Alice, no excerto 1, revela duas ações de planejamento: a) escrever um scripte b) explorar as ferramentas. Isso possibilita ao aprendiz pensar e pesquisar sobre o que vai falar antes de ter que fazê-lo. Também é possível perceber como a estudante relaciona essa affordance com sua ação de regravação, uma outra affordance que será explorada a seguir. No excerto 2, podemos perceber como a possibilidade de planejar permitiu que Bianca tivesse atenção a detalhes da fala. O script elaborado pela estudante foi relido muitas vezes, o que permitiu que ela se tornasse confiante de que estava falando da maneira como desejava. No excerto 3, novamente é afirmado que houve a preparação de um roteiro de fala antes da gravação em si. Esse passo permitiu que Andressa usasse a ferramenta Text to Speech, na qual o usuário pode ouvir como um nativo pronunciaria aquele trecho, tendo a oportunidade de pensar e conferir a pronúncia antes de realizar a gravação.

\subsection{Regravar}

Outra oportunidade de ação percebida pelos estudantes como capaz de desenvolver suas habilidades orais é a de "regravar". Ao se engajarem nas tarefas semanais do curso, os aprendizes perceberam, sem a interferência dos professores, que as ferramentas digitais os permitiriam gravar e regravar suas vozes o quanto quisessem. Essa affordance parece ter feito com que os alunos realizassem a mesma tarefa diversas vezes, fazendo com que eles se tornassem capazes de analisar, monitorar e refletir sobre suas produções orais em língua inglesa. Nos enunciados abaixo, temos as vozes de alguns estudantes sobre a percepção dessa ação de aprendizagem. 
4. Não identifiquei erros em minha primeira gravação, acho que foi porque tive muito trabalho com ela, então a regravei algumas vezes. Apenas identifiquei um pouco de nervosismo na fala, ficaria melhor se a fala tivesse sido mais natural. (Lucas)

5. Eu tive alguns erros de pronúncia, e agora estou mais atenta ao ouvir e gravar várias vezes até obter a pronúncia correta. Agora eu consigo falar sem cometer o mesmo erro. (Fernanda)

6. Aliás, uma coisa que também aprendi é que, no começo, eu tentava fazer algum rascunho ou ensaio e gravava várias vezes, já nas últimas tarefas, eu gravava no máximo duas vezes e já conseguia identificar meus próprios erros de pronúncia e corrigia os mesmos com mais naturalidade durante as tarefas. (Mateus)

No excerto 4, Lucas afirma que "teve muito trabalho" com umas de suas tarefas por tê-la regravado diversas vezes, o que sinaliza que o processo de regravação fez com que o aluno aprimorasse suas produções orais. No mesmo sentido, no excerto 5, Fernanda menciona que o ato de gravar várias vezes até pronunciar as palavras da maneira adequada a deixou mais atenta para sua produção oral. Para a aprendiz, a ação sobre essa percepção possibilitou que ela superasse seus erros. Já no excerto 6, Mateus também menciona a affordance de regravar, mas deixa claro que, na medida em que o curso avançava, a quantidade de vezes que ele regravava diminuía, o que parece sinalizar que o participante percebeu melhoras em sua fala.

\subsection{Identificar as próprias dificuldades}

Os alunos relataram a percepção da affordance de reconhecer suas próprias dificuldades ao poderem ouvir suas gravações. Além disso, eles foram capazes de perceber seus pontos fracos no desenvolvimento da fala em inglês. Essa conscientização é importante para que o aluno possa orientar seus estudos naquilo que deve ser de fato aperfeiçoado.

7. Para mim, uma experiência singular, principalmente pela oportunidade de gravar e ouvir minha voz, perceber as dificuldades e erros na pronúncia. (Eduardo)

8. Achei as ferramentas introduzidas bem interessantes, não gostei muito dos avatares, mas a ideia de gravar áudios pessoais e poder ouvir os colegas foi bem enriquecedor. Porque é possível identificar nossas dificuldades e é notável o desenvolvimento oral com a prática. (Ângela) 
9. "Novamente, eu optei por não seguir um roteiro escrito para me forçar a falar mais naturalmente e perceber quais são minhas dúvidas e minhas dificuldades". (Thaís)

No excerto 7, Eduardo afirma que identifica essa affordance ao escutar sua voz após gravar os exercícios, e destaca o importante papel da ferramenta nesse processo, o qual não seria possível em uma conversa face a face. É possível perceber ainda como os alunos relacionam a superação dessas dificuldades com o desenvolvimento de uma fala mais natural. Ângela, no excerto 8, afirma que se escutar e escutar aos colegas possibilita identificar essas dificuldades, e que a prática constante não apenas da fala, mas também do ouvir, permite que ela desenvolva sua habilidade oral. Já a estudante Thaís, no excerto 9, consegue reconhecer suas dificuldades quando grava sem o uso de um roteiro escrito, similar a uma situação comunicativa face a face. Ela afirma que dessa maneira alcança uma fala mais natural e consegue identificar suas reais dúvidas e dificuldades linguísticas.

\subsection{Identificar erros de pronúncia}

O uso das tecnologias digitais permitiu que os estudantes percebessem especialmente os próprios erros de pronúncia ao escutar suas gravações. Essa affordance deixa claro que, ao serem capazes de se ouvir, eles puderam avaliar a forma como articulavam as palavras e frases na língua inglesa e identificar os erros que eles mesmos cometiam, como podemos perceber nos excertos a seguir.

10. Elas auxiliam no desenvolvimento oral, na medida em que permitem ouvir sua pronúncia e perceber erros que muitas vezes não percebemos enquanto falamos. (Mariana)

11. Eu já utilizei a ferramenta "Vocaroo" com o meu aluno de aula particular e foi muito interessante. Ele pôde observar os seus erros de pronúncia e tentar novamente até falar da forma como desejava. (Camila)

12. Quando nos gravamos, e depois que escutamos o áudio novamente, notamos muitos erros (gramaticais e de pronúncia) que não havíamos percebido antes, portanto é uma boa oportunidade para corrigir, além da imensa ajuda que temos semanalmente com feedback. (Valéria)

No excerto 10, Mariana relata que percebeu erros de pronúncia que ela não seria capaz de identificar durante sua fala sem o uso das ferramentas 
digitais. Camila, no excerto 11, relata não a sua, mas a percepção de um de seus alunos (alguns estudantes da disciplina já eram professores em serviço). Ela percebeu que, utilizado a ferramenta Vocaroo, seu aluno pôde identificar e corrigir seus erros de pronúncia. Da mesma forma, no excerto 12, Valéria explica que constatou os próprios erros ao escutar sua gravação e que isso possibilitou sua autocorreção. Podemos notar, portanto, que os estudantes reconheceram que foram capazes de melhorar seus desempenhos orais após a percepção de seus erros.

\subsection{Praticar a compreensão oral}

Outra possibilidade percebida pelos participantes, ainda que em menor ocorrência, é a prática da compreensão oral. Ela aconteceu quando os alunos precisaram ouvir seus colegas e compreender o que eles disseram anteriormente para então realizar sua parte da tarefa e comentar no trabalho da outra pessoa.

19. Comentei nas atividades dos colegas, e foi também muito produtivo, porque dessa forma é possível desenvolver nossas habilidades de listening. (Alice)

20. Famous person avatar também foi interessante, pois força a saber o que o áudio quer dizer, para assim podermos interagir com os colegas e descobrir qual o famoso em questão. (Sofia)

21. Mais uma vez usamos o VoiceThread. Li sobre o vocabulário relacionado a sentimentos e emoções. Ao assistir o vídeo, discordei muito como as ideias de desrespeito e empatia são colocadas e escrevi sobre isso. Gravei muitas vezes, diretamente no vídeo. A ferramenta é interessante para prática auditiva e de expressão oral, com a qual podemos ainda trabalhar opiniões, discussões e conselhos. (Antônia)

No excerto 19, Alice reconhece que a necessidade de ouvir os áudios dos colegas para comentar as atividades a ajudou a praticar também a compreensão oral. No excerto 20 , Sofia descreve uma atividade na qual os alunos gravam um áudio para o avatar de uma pessoa famosa para que os colegas possam ouvir e descobrir quem é a pessoa descrita. Similar ao que é descrito no excerto 19, a aluna identifica que precisa se esforçar para compreender o áudio a fim de interagir com os colegas, e isso a ajuda a desenvolver a compreensão oral. Já no excerto 21, a aluna fala especificamente sobre a ferramenta Voice'Thread, pela qual é preciso 
assistir a um vídeo e comentá-lo. Para tanto, ela precisa compreender o que foi dito no vídeo e refletir sobre o assunto; neste caso a aluna percebeu a oportunidade de desenvolver não só as habilidades auditivas e orais, como também estruturas linguísticas específicas de diferentes gêneros discursivos.

\subsection{Praticar em diversos lugares}

Os cursos on-line estão se tornando mais comuns e a mobilidade é uma das affordances dessa modalidade de estudo. Além de poder praticar a língua em qualquer lugar, o aprendiz também pode fazê-lo no seu próprio ritmo, com suas próprias estratégias de aprendizagem e focando nos pontos que precisa desenvolver mais. Os excertos apresentados a seguir ilustram a percepção dos agentes sobre essa affordance.

16. As ferramentas on-line são boas para aprendizagem porque podemos utilizá-las em qualquer lugar. (Ângela)

17. Posso acessar em qualquer lugar, sempre ouvir o que eu disse e a pronúncia de outras pessoas também. (Andréia)

18. As ferramentas podem ter outros usos, para aprendizes, por exemplo, permitir interação com pessoas de outros países que têm o inglês como sua língua materna. (Mariana)

No excerto 16, Angela destaca a possibilidade de utilizar a ferramentas em qualquer lugar, e Andréia, no excerto 17, acrescenta a vantagem de poder ouvir não só a própria pronúncia, mas a de outros falantes também. Já Mariana, no excerto 18, chama atenção para o uso das ferramentas como uma forma de interagir e praticar a língua com falantes nativos da língua inglesa, o que a permite comunicar-se com falantes de uma região sem estar fisicamente presente nela. Como podemos ver, as tecnologias digitais facilitam o estudo não apenas pela mobilidade física do aluno, que pode estudar e praticar a língua em qualquer lugar, mas também por permitir que o aluno experiencie situações reais de interação com culturas e indivíduos estrangeiros sem ter que se deslocar.

\subsection{Interagir}

Por fim, a última categoria de affordances percebidas nessa pesquisa refere-se à possibilidade de uso das ferramentas digitais para interação entre 
agentes. Na percepção dos estudantes da disciplina, o uso das ferramentas permitiu que eles interagissem no ambiente virtual. Essa percepção refere-se tanto às tecnologias em si quanto ao design pedagógico do curso, que previa fóruns semanais. Havia uma rede conectada, em que os agentes, presentes virtualmente naquele ambiente, conseguiam interagir, como podemos perceber nos excertos abaixo:

22. Gostaria de dizer que achei muito interessante a interação nos fóruns, os colegas comentando e interagindo. (Priscila)

23. Durante essa experiência deu para aprender diversas ferramentas, e o mais importante, o aprendizado no convívio com os outros colegas e professores, porque através da proximidade que tivemos com as atividades, ficou mais fácil interagir com os colegas e, por meio disso, o aprendizado fluiu melhor. (Lucas)

24. Acredito que as ferramentas digitais têm grande potencial para o ensino de línguas, porque permitem novas formas de interação e podem nos ajudar a ressignificar o ensino de línguas, muitas vezes trazido por meio de uma abordagem muito tradicional e com pouca abertura para o uso de tecnologias digitais. (Marta)

No excerto 22, Priscila anuncia sua percepção de que havia interação no ambiente, com os "colegas comentando e interagindo". Já no excerto 23, Lucas deixa clara sua percepção de que a aprendizagem ocorreu por meio do uso da língua, no convívio e interação com os demais agentes do ambiente virtual. Por fim, no excerto 24, Marta deixa clara a sua convicção de que as ferramentas digitais propiciam novas formas de interação na aprendizagem. É importante destacar que, em se tratando de um ciberespaço, o conceito de interação configura-se como bastante abrangente, já que se torna possível interagir não só com outros agentes, mas também com as próprias ferramentas e o ambiente em si.

\section{Considerações finais}

Em nossa análise, ficou evidente que os estudantes perceberam diversas affordances para desenvolver suas habilidades orais em língua inglesa. Concluímos também que as affordances percebidas pelos agentes referiam-se tanto às ferramentas quanto ao ambiente e ao design pedagógico da disciplina, o que vai ao encontro da perspectiva ecológica, que concebe a aprendizagem 
como um fenômeno complexo que compreende a relação entre o sujeito e o ambiente em que está inserido.

Para o grupo de estudantes em questão, a experiência com o uso de ferramentas digitais naquele ambiente virtual permitiu que eles planejassem suas produções orais, regravassem, identificassem suas dificuldades e erros de pronúncia, praticassem a compreensão oral, em diversos lugares, e interagissem. Essas affordances foram percebidas pelo grupo de aprendizes em questão como oportunidades de ação efetivas para o desenvolvimento de habilidades orais. Como já dito, as affordances percebidas estão bastante mescladas e conectadas, o que evidencia a complexidade do processo de aprendizagem. Ao mesmo tempo em que sinalizam um caminho percorrido por esses aprendizes, os dados sinalizam uma não linearidade nesse processo.

Percebemos também uma relação entre a percepção e a ação sobre as affordances com as identidades e emoções dos aprendizes. É notável que, na medida em que iam percebendo e agindo sobre as oportunidades que encontravam, os estudantes iam se tornando mais seguros, motivados, confortáveis e confiantes; menos envergonhados, frustrados, estressados e tímidos. Acreditamos que isso tenha ocorrido pela possibilidade trazida pelas affordances de que as vozes de todos os alunos fossem ouvidas, tanto por eles quanto pelos outros agentes sem nenhuma restrição de tempo, o que não necessariamente ocorre em um ambiente de sala de aula presencial. Sendo assim, acreditamos que mais pesquisas e investimentos nas tecnologias digitais devam ser conduzidos para que se possa buscar por mais maneiras de ensinar e aprender línguas estrangeiras.

Terminamos este artigo com o relato de uma estudante que sintetiza bastante essa relação entre o reconhecimento de affordances de tecnologias digitais e as identidades e emoções de aprendizes de inglês.

23. Pude notar grandes mudanças na minha produção oral durante o curso e também notei mudanças significativas na maneira com que eu me preparava para cada atividade. Inicialmente, eu costumava ouvir a produção de vários colegas para medir como eu deveria gravar meus áudios. Senti a necessidade de fazer scripts nas primeiras atividades, porque quando eu tentava gravar os áudios sem script eu gaguejava demais e soava muito confusa. Também tive a impressão que minha pronúncia ficava comprometida por causa do nervosismo, o que, ironicamente, me fazia ficar mais nervosa. Depois de passadas algumas semanas me senti mais confortável no ambiente da sala e percebi que, assim como eu, meus colegas também cometiam erros. Diferente de mim, muitos deles 
não pareciam tão incomodados com os erros e falavam com muito mais naturalidade. Foi assim que passei a tentar gravar meus áudios sem script. Normalmente, eu elaborava a resposta mentalmente e depois gravava o áudio. A princípio, fiquei um pouco nervosa e incomodada com as pausas naturais da minha fala ou mesmo quando eu tinha que repetir alguma palavra para corrigir a pronúncia, mas depois passei a não me preocupar tanto com isso. Acredito que falar sem elaborar scripts me permitiu desenvolver a naturalidade da minha produção oral em inglês e, além disso, me ajudou a ganhar confiança para compartilhar minha produção em um ambiente on-line. (Marta)

\section{Agradecimentos}

Agradecemos a Vera Menezes de Oliveira e Paiva pela leitura preliminar e pelas importantes considerações feitas a este artigo, a Fundação de Amparo à Pesquisa de Minas Gerais (Fapemig) e ao Conselho Nacional de Desenvolvimento Científico e Tecnológico (CNPq) pelo apoio financeiro durante a pesquisa.

\section{Referências}

ARAGÃO, R. C. Emoções e ações de professores ao falar inglês no WhatsApp. Revista Brasileira de Linguística Aplicada, Belo Horizonte, v. 17, n. 1, p. 83-112, 2017. Disponível em: <https://goo.gl/UeUxEr>. Acesso em: 3 ago. 2017.

ARAGÃO, R. C.; PAIVA, V. L. M. O.; GOMES JUNIOR, R. C. Emoções no desenvolvimento de habilidades orais com tecnologias digitais. Calidoscópio, São Leopoldo, no prelo.

CHEMERO, A. An outline of a theory of affordances. Ecological Psychology, London, v. 15, n. 2, p. 181-195, 2003. DOI: https://doi.org/10.1207/ S15326969ECO1502_5

CHEN, H. H. Developing and evaluating an oral skills training website supported by automatic speech recognition technology. ReCALL, New York, v. 23, n. 1, p. 59-78, 2011. DOI: https://doi.org/10.1017/S0958344010000285

DIAS, R.; PIMENTA, S. M. O. Technologies, literacies in English oral communication and teacher education: an empirical study at the university level. Revista Brasileira de Linguística Aplicada, Belo Horizonte, v. 15, n. 3, p. 711-733, 2015. Disponível em: <https://goo.gl/rhSbrJ>. Acesso em: 3 ago. 2017. 
DENZIN, N. K.; LINCOLN, Y. S. A disciplina e a prática da pesquisa qualitativa. In: DENZIN, N. K.; LINCOLN, Y. S. O planejamento da pesquisa qualitativa: teorias e abordagens. Porto Alegre: Artmed, 2006. p. 15-47.

DÖRNYEI, Z. Research methods in applied linguistics: quantitative, qualitative, and mixed methodologies. Oxford: Oxford University Press, 2007.

GIBSON, J. J. The ecological approach to visual perception. Hillsdale, NJ: Lawrence Erlbaum, 1986.

HOLIDAY, A. Doing and writing qualitative research. London: Sage, 2002.

HUI-YIN, H.; SHIANG-KWEI, W. S; COMAC, L. Using audioblogs to assist English-language learning: an investigation into student perception. Computer Assisted Language Learning, Abingdon, v. 21, n. 2, p. 181-198, 2008. DOI: https://doi.org/10.1080/09588220801943775

KENNEWELL, S. Using affordances and constraints to evaluate the use of information and communications technology in teaching and learning. Journal of Information Technology for Teacher Education, Abingdon, v. 10, n. 1-2, p. 101-116, 2001. DOI: https://doi.org/10.1080/14759390100200105

MENEZES, V. Affordances for language learning beyond the classroom. In: BENSON, P.; REINDERS, H. Beyond the language classroom. Basingstoke: Palgrave McMillan, 2011. p. 59-71. DOI: https://doi. org/10.1057/9780230306790_6

MURRAY, G.; FUJISHIMA, N. Social language learning spaces: affordances in a community of learners. Chinese Journal of Applied Linguistics (Quarterly), Berlin, v. 36, n. 1, p. 139-159, 2013.

PAIVA, V. L. M. O. Tecnologias digitais para o desenvolvimento de habilidades orais em inglês. 2014. 28 f. Projeto de pesquisa CNPq (Produtividade em Pesquisa - PQ - 2014) - Universidade Federal de Minas Gerais, Belo Horizonte, 2014.

PETRAKOU, A. Interacting through avatars: virtual worlds as a context for online education. Computers \& Education, Amsterdam, v. 54, n. 4, p. 1020-1027, 2010. DOI: https://doi.org/10.1016/j.compedu.2009.10.007

SELIGSON, P. Helping students to speak. London: Richmond, 1999.

STOFFREGEN, T. A. Affordances as properties of the animalenvironment system. Ecological Psychology, London, v. 15, n. 2, p. 115-134, 2003. DOI: https://doi.org/10.1207/S15326969ECO1502_2 
VAN LIER, L. From input to affordance: social-interactive learning from an ecological perspective. In: LANTOLF, J. P. Sociocultural theory and second language learning. Oxford: Oxford University Press, 2002. p. 155-177.

VAN LIER, L. The ecology of language learning: practice to theory, theory to practice. Procedia: Social and Behavioral Sciences, Amsterdam, v. 3, p. 2-6, 2010.

VOLLE, L. M. Analyzing oral skills in voice e-mail and online interviews. Language Learning \& Technology, Santa Barbara, CA, v. 9, n. 3, p. 146-163, 2005. 